Note

\title{
Good practice: Scaffolded, Collaborative Project-based Learning
}

\author{
Beata Jones \\ Honors Faculty Fellow, Texas Christian University, Fort Worth, Texas, U.S.A. \\ Correspondence: $\underline{\text { b.jones@tcu.edu }}$
}

Received: 2 December 2018; Accepted 12 December 2018; Published: 7 January 2019

Keywords: authentic problems, bounded freedom, challenge, collaboration, deeper learning, project-based learning, scaffolding instructions, honors

Note to reader: honors keywords (see introductory article of this issue) in italics in the text

\section{Introduction}

'If you want to build a ship, don't drum up people to collect wood and don't assign them tasks and work, but rather teach them to long for the endless immensity of the sea.'

$\sim$ Antoine de Saint-Exupery

Project-based learning ( $\mathrm{PjBL}$ ) is a philosophy of teaching and learning that includes a framework for how we will organize education in the future, according to Markham (2012). The framework involves interdisciplinary knowledge construction while completing a social activity that builds context-dependent self-awareness of learning and knowing (Tamim and Grant, 2013). For clarity purposes, we distinguish between project-based learning and problem-based learning (PBL). While there are many similarities between the two approaches, they both engage students in authentic tasks, are open-ended, involve collaboration, and simulate professional environments, the two approaches differ slightly. According to Donnelly and Fitzmaurice (2005), the key difference lies in the focus of the two strategies. In PjBL, the end artifact developed in the course is the driver of the course planning, implementation, and the evaluation process, while, in $\mathrm{PBL}$, the primary focus of the learning process is on the inquiry (rather than the end product).

$\mathrm{PjBL}$ emerged as one of the most effective active learning instructional practices (Buck Institute for Education, 2018a; Drake, 2012). In PjBL, students confront real-world challenges, collaborate to create solutions, and present their results in a public setting. In $\mathrm{PjBL}$ courses, the project is at the core of the curriculum, involving an in-depth inquiry and requiring revisions of and reflections on the artifacts developed. PjBL typically requires students to toil for weeks or months to complete the work and stresses student voice as well as instructor scaffolding in the course implementation. 
The collaborative project-based learning environment described in this paper occurs in a U.S.-based business school, in an honors section of a core business curriculum course called Business Information Systems. In the United States, there are honors courses that are available to only honors students and there are courses that are required of all the students that can satisfy honors requirements by having students enroll in a special honors section. The honors sections of a regular course typically have somewhat different curriculum and use honors pedagogy to deliver the content. The course described in this paper is an example of the latter. It is required for all students interested in pursuing business education at Texas Christian University (TCU). TCU is a private, midsize university in Fort Worth, Texas. Neeley School of Business at TCU is an Association to Advance Collegiate Schools of Business (AACSB)-accredited undergraduate business program. The class described in this note met for three hours each week over a 15-week period. The students in the class were sophomore business honors students. They received the class with enthusiasm and achieved at a high level. A conference on information systems education also recognized the work described in this paper with a best paper award (Jones, 2015).

\section{Why this good practice?}

The American Association of Colleges and Universities (AAC\&U) considers Collaborative Assignments and Projects as one of the ten high-impact practices that any course or curriculum could apply (Kuh, 2008). High-Impact Practices (HIPs) are techniques for teaching and learning in higher education that have been proven to benefit student engagement and learning among students from diverse backgrounds (Leap Resource Toolkit, 2015).

Figure 1. Essential Design Elements for Project-Based Learning

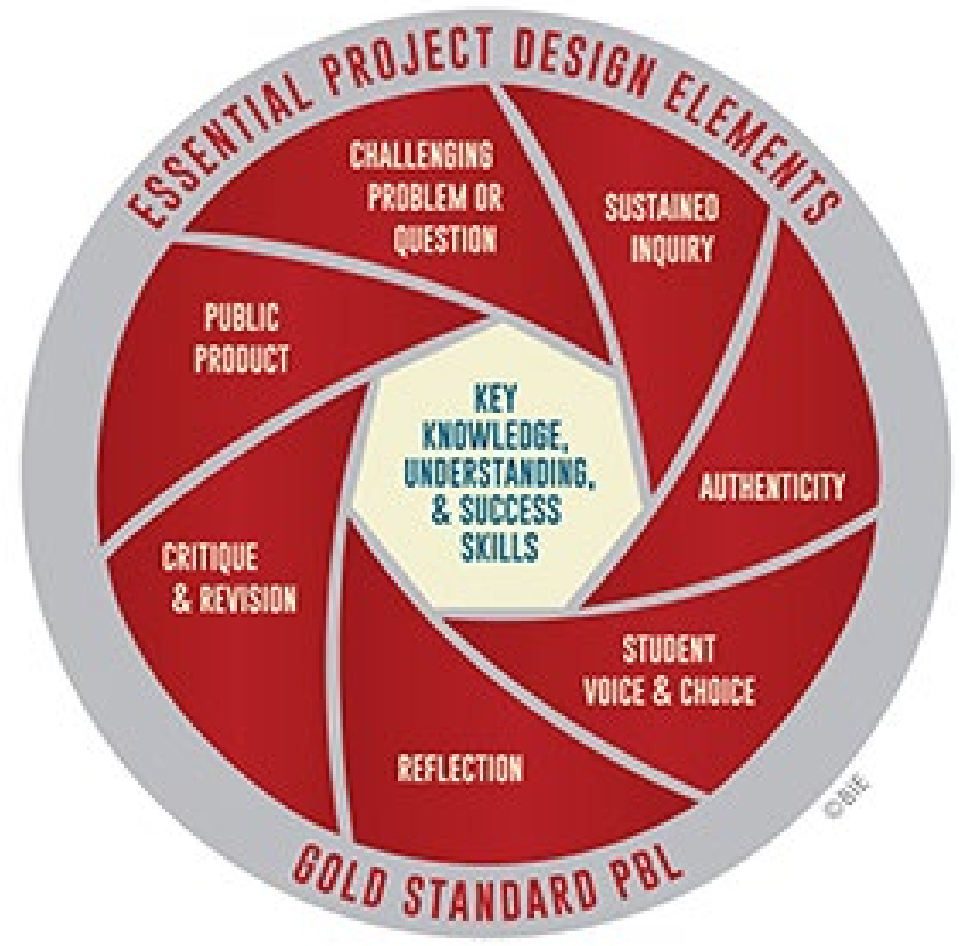

Source: Adapted from Mergendoller, Boss \& Larmer, 2015 
Working on projects in an honors course or program is a common practice in the U.S. and the Netherlands, as demonstrated in this issue of the Journal of the European Honors Council. However, completing a project as a part of a course is not equivalent to projectbased learning. Project-based learning pedagogy requires instructors to include specific elements, as demonstrated in Figure 1. By giving students a fair amount of choice and responsibility, a sense of purpose, and practical activities that engage their hearts and minds over an extended period, PjBL leads to a deeper understanding, a greater retention of knowledge, and improvement in both teachers and students' enjoyment of learning (Strobel and van Barneveld, 2009; Buck Institute for Education, 2018b; Kingston, 2018). Project-based learning does not respond to a classroom challenge for the teacher, but it presents an opportunity for the teacher and the students to learn more, to acquire more relevant, 21st century skills that respond to the shifts in our economies (e.g. Seeley Brown, 2011; Setser and Morris, 2015), and to enjoy the process of learning: 'The new 21st century education (...) necessitates a new kind of teaching, one that focuses on learning how to learn - the single most important skill anyone can master' (Davidson, 2017). Project-based learning is thus a great vehicle for developing these important skills. PjBL helps students 1) handle complex problems and inquiry, 2) develop into better independent critical thinkers and innovators, and 3) develop collaboration and presentation skills - all key skills in our new economy. Students can develop these key skills without establishing any special environments for innovation at the college or university. Teachers can incorporate PjBL in almost any classroom with a little course re-design at a relatively low cost.

\section{Target group and target group size}

While this note presents findings from the project-based learning implementation with the second year honors students at a business school, collaborative project-based learning may be applied within any course offered by any college or program, regardless of course level, disciplinary focus, or class size. I have used this pedagogy in various other settings: with first and second year students in a study abroad course, with third year students in a specific discipline-related course, and in a number of third and fourth year interdisciplinary honors colloquia courses. Class sizes varied from 14 to $40+$ students.

The practice described in this note carries three American credit hours, though a faculty member could implement project-based learning principles within any course, regardless of the number of credit hours. The practice is highly scalable and faculty can design courses around projects that require specific number of hours, per local requirements of their university, as needed.

\section{Educational design (structure)}

Scaffolded, Collaborative, Project-based Learning is a learning environment consisting of 1) project-based learning, 2) collaboration, and 3) instructional scaffolding. I describe each one of the three elements of this learning environment below, first theoretically and then with an example from a course.

\section{Theoretical Basis of Project-Based Learning}

1) Project-based learning requires that a teacher designs a project for the students with the following eight research-based elements (Mergendoller et al., 2015): 
a. Challenging Problem or Question - The course instruction should start with a question or a problem rather than a broadcasting of content. The problem or question should not have an easy answer that students can quickly derive by simple knowledge retrieval. The challenge should be relevant and engaging for the students without being intimidating, so they have a real need to obtain the answers and are capable of doing so. Teachers select the real-world challenge and should write the overarching problem in the form of a question.

b. Sustained Inquiry - The problem presented to the students has to be complex enough to require iterative inquiry over an extended period, which is more than just a few days or a week of a semester-long course. Students should investigate possible answers with the help of a range of available resources, using their critical thinking and/or creativity skills. They should research, assess the value of the information they found, and design solutions collaboratively.

c. Authenticity - Since authentic problems increase student motivation and learning, assigning authentic problems for the project is key to its success. Authentic problems can include those a professional in a domain area of study might face in his or her day-to-day work; it can involve use of real-world processes, tools, or techniques; it can have a tangible impact on others; it can address students' own interests or concerns or a combination of the aforementioned.

d. Student Voice and Choice - Giving students a voice to determine what they will work on in the project creates a sense of ownership, which results in their greater motivation to work harder. Letting students decide aspects of what they will work on and what tools or resources they will use will help with project outcomes. Teachers' willingness to adjust the challenge as needed, based on student feedback during the semester, is key to success.

e. Reflection - Throughout the project, both students and teachers should reflect on what, why, and how they are learning. Reflection may occur in class, in a blog or journal, or as a part of a formative assessment for the students/teachers. Reflection on experiences is key to one's learning.

f. Critique and Revision - Another key to a high quality outcome of the project is iteration and revision. Students should learn how to give and receive feedback and how to learn from it. Peers, faculty, or outside project stakeholders might offer formative feedback to the students in the form of comments or checklists/rubrics.

g. Public Product - In project-based learning, students always create a 'product' to share publicly. The product can be a performance, a tangible item, or a presentation of a solution. Public sharing creates a degree of student anxiety, which translates into student motivation to do well.

2) Collaboration - 'Collaborative learning combines two key goals: learning to work and solve problems in the company of others and sharpening one's own understanding by 
listening seriously to the insights of others, especially those with different backgrounds and life experiences' (Kuh, 2008). Collaborating with peers in solving problems prepares students to deal with the complex problems they will encounter after graduation. While students often do not appreciate group work, such work can, if implemented well, be enjoyable and lead to knowledge gains that last for an extended period (Buche, 2013).

3) Scaffolding refers to instructional techniques that provide support for student learning (Edglossary, 2015). Scaffolding techniques typically yield higher level of skill acquisition, and faculty slowly remove them over time, shifting the responsibility for learning onto the students. Research considers scaffolding to be an essential element of effective teaching. Some examples of scaffolding include giving a vocabulary lesson or test before applying the concepts in a problem, giving a model or an exemplar project for students to develop a better understanding of expectations, providing formative feedback, and coaching.

\section{Example of Project-Based Learning within a Business Information Systems Course}

1) Project-Based Learning implementation within a course included the following elements:

a. Challenging Problem or Question - On the first day of class, the instructor informed students of the nature of the course and added that the course would be a lot of work, but that, at the end, they would have accomplished feats beyond their expectations, thereby increasing employability. The faculty member also told the students that she intended to achieve the course objectives by applying new instructional methods relevant to 21st-century learners, assuming that learning occurs both inside and outside the boundaries of the physical classroom. The faculty member then distributed the project document, which consisted of approximately 30 pages of project details: the scenario, description of various deliverables, assessment forms, and samples of previous work. The instructor asked the students to prepare an information systems global expansion plan for a small business of their choice, which was the key challenge and the core of the class curriculum.

Throughout the course, the instructor treated students as business analysts working for a company on a project requiring tackling real problems facing companies, and producing tangible outcomes: a written report, an information system prototype, a collaborative website, and a project presentation. To set the tone for the remainder of the semester, the professor asked students on the first day of class to complete a new hire form instead of the usual student information sheet, and she continually referred to students as analysts.

b. Sustained Inquiry - The syllabus for the course contained a detailed project timeline with multiple intermediate due dates, and students needed to implement a SharePoint calendar with alerts for all the due dates. The entire course revolved around the student project, integrating a traditional business information systems curriculum. To enable students to construct knowledge with multiple perspectives in mind, the instructor not only diversified teams by major but also assigned 'readings' that represented different genres of resources: primary research articles, TED talks, 
video lectures, e-books, popular press articles, and websites. About $70 \%$ of the course was production-focused, including the various project deliverables and final adventure, plus some of the student engagement deliverables - LinkedIn Profile and Tech Talk.

c. Authenticity - The project deliverables included authentic products that a business information systems analyst might prepare: a written report with recommendations for company expansion, suggestions for various technology implementations, a process model, a design for a mobile app, and other features (Jones, 2015).

d. Student Voice and Choice - The project called for teams of students to pick real companies for which they wanted to conduct their inquiry as business analysts, taking into consideration the team members' common interests and passions. Not only did the teams pick a company for which they chose to "consult" based on their common interests and passions, but each student delivered an informal, five-minute Tech Talk at the beginning of class, based on his or her personal interest, connecting the topics covered in class to current events and their major field of study.

e. Reflection - With each topic in the course and a new project part assignment, the instructor reflected in class with the students on the relevance of their learning to the business world and to the students personally. Additionally, students completed three reflections blogs, commenting on their learning, and two individual status reports pertaining to the project, which allowed them to share their progress and suggest project improvements.

f. Critique and Revision - Periodically, the instructor provided formative feedback via SharePoint on students' weekly deliverable drafts, which allowed the students to better understand expectations and see how they could improve their work. Additionally, students received peer feedback at different points in the course. Toward the end of the semester, each team met out of class with the faculty member for a thirty-minute consultation to go over their entire project, ask questions, and report status. The instructor required the students to receive formative feedback on the project's final written report from the university's writing center and on the project's presentation from the business school's professional development center that routinely provides student presentation coaching.

g. Public Product - the students presented their final project pitches in class and shared their presentations on a public presentation-sharing website, Slideshare, which is a part of LinkedIn. Additionally, they shared their presentations and various artifacts developed in class with the companies they consulted for to receive feedback.

\section{2) Collaboration}

a. Within Team Collaboration - The instructor formed semi-random teams during the first week of classes, thus assuring the highest degree of heterogeneity by major and gender. Each team received a SharePoint site with the assignment to build it out during the course, supporting team collaboration throughout the project. 
Periodically, during the first five minutes of each class, teams reflected on the group process and self-evaluated using the peer evaluation form at the end of the semester. Also periodically, the teams conducted stand-up meetings, reporting on what was going well, what was not going well, bottlenecks, and what they could do better. Twice during the semester, students submitted an individual status report with information similar to that of the standup meeting.

b. Collaboration with Faculty - The faculty member was available outside of class to answer students' questions via email, a Facebook group, or Skype, creating more 'class time' through social proximity. For informal class communications, the instructor constructed a closed Facebook group where students could instantaneously connect with classmates and the professor. Initially, the instructor asked students to upload their visual résumé to the platform for a digital icebreaker, so students and the instructor could get to know each other. The class then used the platform to upload Tech Talk PowerPoints, often resulting in continued conversations on the topic outside of class as interest sparked or new developments occurred.

c. Open Networking - To show the relevance of the material studied in the course, the instructor openly networked the course. Students attended a LinkedIn Workshop and then built their profile to connect with professionals, each other, and the instructor. Professionals spoke in class, but the course also expected students to attend a relevant speaker event outside of class, sponsored by the career services office, the Association for Information Systems professional student organization, or by other organizations. Through outside events, students made connections between classroom knowledge and relevant professional development opportunities. Through links to students' final adventures posted on a Business Information Systems Facebook page at https://www.facebook.com/INSC20263, liked by students from around the world, course attendees could see the relevance of their work and their shared purpose with others.

\section{3) Scaffolding}

a. Teambuilding - With the heterogeneous teams in place, students participated in a teambuilding workshop in class and then had to complete a team contract and team résumé for the following class period. The teambuilding workshop facilitated a conversation within the group about communication styles present within the group and how to best work with each member. The team contract set the group collaboration expectations for the semester, while the team résumé was a fun way for students to share personal information and find common ground.

b. Tinkering Workshops/Labs - The business reference librarian constructed an online resource for the project, available at http://libguides.tcu.edu/BusinessInformationSystems, and conducted an in-class workshop to help students become effective online researchers. Various technology tinkering labs throughout the semester allowed the students to experiment with new technology and be creative without incurring any grade penalties. 
c. Flipped Classroom - As Educause (2012) suggests, 'The flipped classroom is a pedagogical model in which the typical lecture and homework elements of a course are reversed.' The flipped classroom is a pedagogy that is radically transforming education (Bergman and Sams, 2012) and naturally lends itself to implementation in honors courses. Various flipped classroom models exist, some of which involve watching pre-recorded lectures or reading assigned material prior to class and then using class time for application of the material studied at home. This approach not only puts more of the responsibility for learning on students, but it gives them greater impetus to tinker with the ideas. The flipped classroom changes the role of faculty in the course from 'sage-on-the-stage' to 'guide-on-the-side' and the role of students from passive participants in the education process to engaged collaborators, leading to greater mastery of the material. Below is an account of the flipped classroom environment used in the course.

i. At Home: For homework, students completed assignments involving e-book readings with quizzes (Pearson's MyISLab), labs (Pearson's MyITLabsimulations and assessments), and research, attended speaker events, participated in LinkedIn workshops, and worked on the project part drafts.

ii. In Class: After an opening Tech Talk, students used class time for project management and to work in groups on weekly deliverables that required a familiarity with the homework material. Speakers and tinkering workshops/labs changed the pace of the course occasionally.

\section{Student assessment}

Students received a set of clear expectations for each deliverable of the project. The professor provided detailed evaluation forms/rubrics showing point allocations for each aspect of each deliverable. Additionally, she indicated that she would use the team peer evaluation findings to adjust the grades at the end. The professor used peer evaluations together with a division of work section of the written deliverable, which reported on each team member's contributions in the project, to adjust the final individual grades.

\section{Experiences}

1. Student Satisfaction

Students received the course with enthusiasm. The quality and caliber of their team deliverables, as well as the learning they took away from class, surprised them. Figure 2 below shows student perceptions of teaching (SPOT) scores for the course compared to the averages in the department, division, and school. The scale used was from 1 to 5 , with 1 representing 'Strongly Disagree' and 5 representing 'Strongly Agree'. 
Figure 2. Honors student perceptions of teaching-average scores (Avg red) for the PjBL course, compared to the averages in the department (INSC Avg, blue), division (Div avg, yellow) and school (School Avg, green). Note: Avg stands for average score.

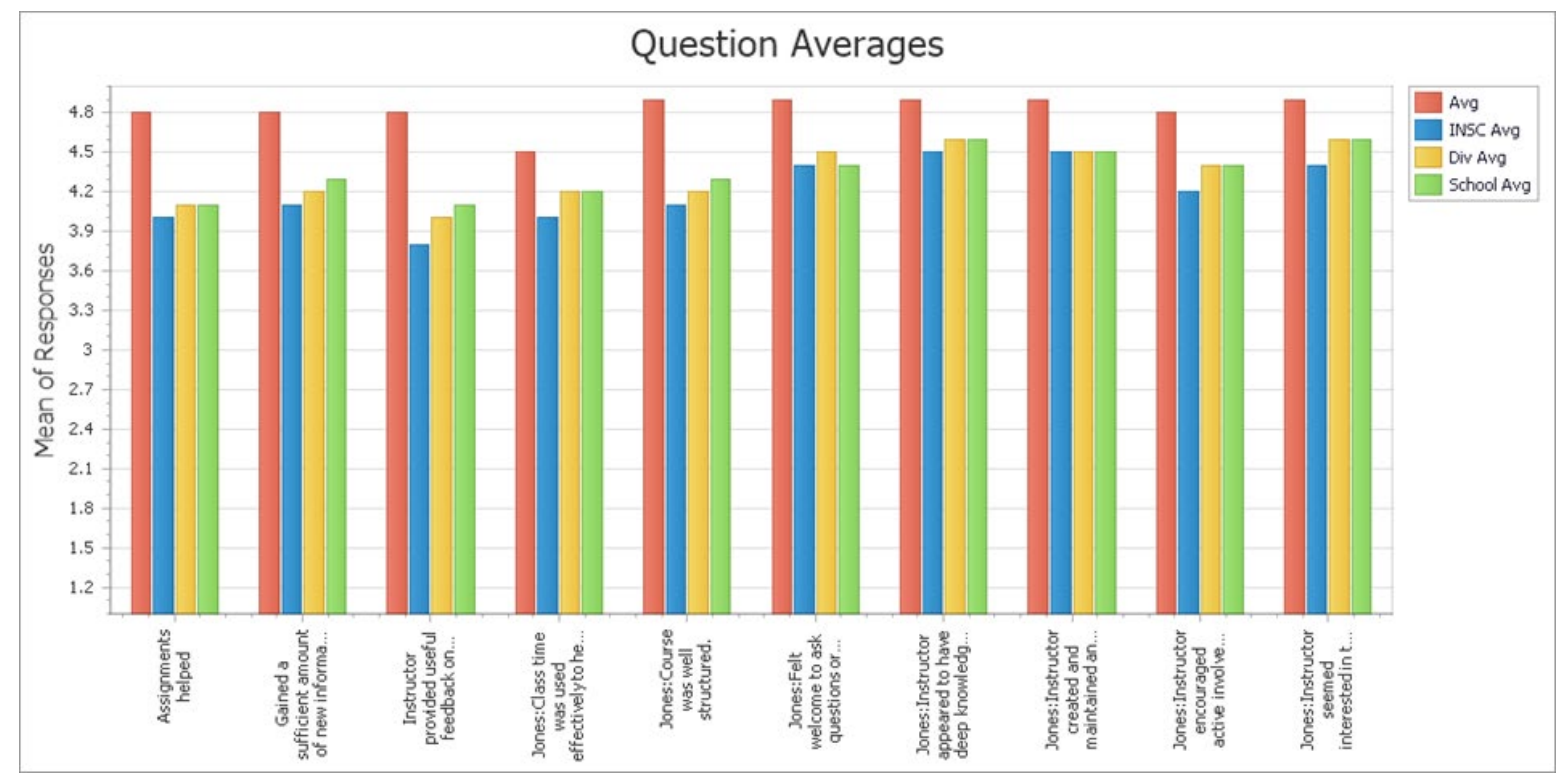

Almost $100 \%$ of the students either agreed or strongly agreed with the statements provided on the anonymous SPOT survey. Overall, the professor's scores on the SPOT survey greatly exceeded the average scores earned by the department, division, and school. Quotes from students' anonymous comments section follow:

- 'By far the best class I've taken at TCU thus far!'

- 'Current setup is very conducive to learning.'

- 'The flipped classroom philosophy was interesting. It required a lot of the students, but it was manageable because the professor was easily accessible.'

- 'The class was very well structured so there was never any confusion on what needed to be done but at the same time there was lots of opportunities for us to make it what we wanted. I feel that I learned the most in this class as far as real-life applications.'

- 'Outside of class readings, quizzes, and assignments were great. I learned a lot about the subject.'

- 'Well-thought-out syllabus. Clear rubrics for every graded assignment. No confusion on due dates.'

- 'The big semester project was interesting; I gained many soft skills in working in a group. The textbook/as well as the project forced me to learn the more technical aspects.'

- 'The consulting project was the bulk of the work, which was a bit intimidating but worked well. I learned a lot about team dynamics as well as information systems by integrating class lessons with the project.' 


\section{Achievement of Learning Outcomes}

The average GPA in the course was 3.77, indicating high level of faculty satisfaction with the student performance in the course. A typical, traditional section of this course yields an average GPA of about 3.0. These results are consistent with the finding of Strobel and van Barneveld (2009), who reported that, when implemented well, PjBL can increase long-term retention of material and replicable skills, as well as improve teachers and students' attitudes towards learning. We do not have results regarding our students' longterm retention.

\section{Industry Relevance}

The instructor sought input from two local consulting recruiters before initiating the project. Both consulting firms received the project with enthusiasm and provided minor feedback for improvement, which the professor incorporated into the assignment instructions. Some of the students interning with these consulting companies reported having received a similar type of a project as a part of their summer internship. Some students shared their results with the companies on which the projects focused and received positive feedback. In several instances, companies adopted parts of the student projects into their day-to-day operations. This feedback demonstrates that even introductory business core courses can make an impact on the business community.

\section{Time requirement for teachers}

Project-based learning courses require commitment of more resources than traditional, lecture-based or discussion-based courses. The approach is time consuming for the instructor as well as the students. For the instructor, this approach to teaching requires a considerable amount of time upfront, designing and planning the various course elements and, during the course, providing formative feedback to the students. For the students, the approach requires time to prepare for each class, which the traditional lecture approach does not need.

\section{Tips for teachers}

\section{Before the course}

A faculty member interested in shifting a classroom often does not know where to begin. He or she might feel discouraged to try a different course approach, especially if the current reward system at his or her institution does not take pedagogical innovation into consideration. Anyone interested in converting a traditional course into a PjBL can find resources available in print (e.g., Markham, 2012) and online (e.g., Buck Institute for Education, 2018c). The worksheet presented in Table 1 might assist faculty in the initial thinking when deciding to implement a PjBL course, while Caruana (2012) offers tips for getting started with scaffolding instructions. 


\section{PROJECT-BASED LEARNING COURSE DESIGN FOR:}

1. Course Objectives/Learning Outcomes:

2. Course Topics/Content Areas/Skills to Develop:

(Consider $21^{\text {st }}$ Century Skills \& Meta-Skills, Such As: Creativity, Communications, Collaboration, Critical Thinking, Empathy, Learning To Learn, Design Thinking, \& Systems Thinking)

3. Write Learning Objectives For Each Topic:

4. Select Essential Questions/Problems Within Each Topic:

5. Write A Real Professional Scenario To Drive The Project Giving Students Voice/Choice, Based On Degrees Of Freedom Available In Your Course:

(Select Partner, If Appropriate, Write Audience, Key Challenge(s), Motivation, Benefits, Deliverables)

6. Write A Detailed Assignment Narrative For Each Topic Within The Scenario, Addressing The Essential Questions/Problems:

7. Determine Assessment Of Learning Objectives For Each Topic's Assignment:

8. Create Prompts To Introduce Each Topic In Class \& To Establish Need to Know:

9. Select Required/Optional Resources For Students To Kick-Start Each Topic's Exploration Prior To Class:

10. Design \& Schedule In-Class Learning Experiences For Each Topic To Showcase Need To Know And Facilitate Completion Of Each Topic's Assignment:

11. Determine \& Design Forms \& Times For Formative \& Summative Feedback: (Faculty, Peer, Professional)

12. Determine \& Design Reflection Forms And Times For Students (e.g., Self-Pre-

Assessment, Team Contract And Resume, Discussions, Blogs/Journals, Papers, Teammate

Peer Evaluations, Other Team's Work Evaluation (Memos, Assessment Forms), Course

Evaluations):

13. Determine Intermediate And Final Deliverables' Timing And Final Project Showcase:

14. Name The Project or Challenge/State Key Inquiry Question:

15. Put Together A Detailed Project Booklet \& Syllabus With All The Information And Make Both Available Via A Collaborative Technology Platform:

Below are some other ideas to consider:

a. Instructor Changing Role - An instructor should become comfortable with his or her changing role from the broadcaster of knowledge to a learning designer, mentor, and coach and comfortable with various technologies that facilitates team/class communication and teamwork, such as Learning Management Systems features that are helpful, social media platforms for building communities, discussion forums, and relevant mobile apps.

b. Collaboration - An instructor should make project collaboration built into the course as a foundational skill and a part of academic work completed. Students learn to work effectively in teams over time, with guidance. Team building needs to be a part of scaffolding offered in a course with collaborative PjBL. If possible, the instructor should promote collaboration - within groups, between groups, between classrooms, 
with different universities, or with professionals - to make learning social and more rewarding.

c. Learning Space - If possible, an instructor should pick a learning space that facilitates teamwork and collaboration, where technology can easily assist the teams.

d. Interdisciplinary Project Nature - If possible, an instructor should try to make the project interdisciplinary, even if the course subject matter is not, by including discipline-specific assignments involving a variety of 21st century literacies -- visual literacy, critical consumption of information, digital storytelling, creativity, etc.

e. Global Scope - If possible, an instructor should focus students on challenges with a global scope to internationalize mindsets and improve global/cultural awareness.

f. Partners - If possible, an instructor should find community partners to help with the project delivery: university support staff, librarians, the writing center, career services, student development services, companies, professional organizations, or other schools.

\section{During the course}

Once a course includes PjBL, an instructor might want to start their course by showing the relevance of project-based learning pedagogy to get student buy-in, which is key to success. There are multiple YouTube videos highlighting the future of work -https://youtu.be/Y9FOyoS3Fag. An instructor can directly relate these videos in class to the importance of implementing PjBL. Another approach might involve having students create a video at the end of a PjBL course, highlighting the relevance of work completed in the course. An example of such a video, from the course I describe in this paper, can be found at https://youtu.be/UqLxEkuY7R8. A group of honors students has created the video in lieu of a final exam as a reflection on the course. I still show this video on the first and last day of my classes to highlight where we are going or where we have been and why.

With each implementation of a PjBL course, an instructor should reflect on its effectiveness and adjust accordingly, changing what has not worked well, based on student feedback and their perceptions.

\section{Tips for students}

Project-based Learning delivers key relevant skills for 21st century work and engages the students and their passions or interests. While the course involves a lot of work, the work completed is satisfying and allows a student to grow. Here are some key tips for students to consider:

1. Embrace Ambiguity - To succeed at work or in life, you will need to depend on your own resources. Your boss or friend/family member will not give you detailed instructions. You will need to ask questions and figure out a sequence of steps to follow to complete a specific endeavor. There is no time like the present to embrace ambiguity and learn how to resolve ambiguity in a given assignment.

2. Build Rapport and Accountability within Your Team Quickly - In a project-based learning course, a team completes the project and not an individual. The amount of work can be challenging for one person, and the skill sets necessary to complete the 
project successfully will vary. Be sure to get to know your teammates' strengths and weaknesses quickly, so you know who can be an asset on which part of the project.

3. Do Not be Afraid to Experiment - When you graduate from college, you will work with new technologies throughout your lifetime. The best way to prepare for that reality is to start experimenting with various programs while you are in college, so you can learn to unlearn and re-learn the new tech quickly.

4. Stay on Track - In a project-based learning course, teams of students need to complete various small deliverables according to a timeline provided by an instructor. Be sure to stay on track, as falling behind can be rather overwhelming at the end of the semester.

\section{Transfer to other programs}

In the last three years, the Neeley School of Business has scaled down and adapted the honors Business Information Systems curriculum to the mainstream course required of everyone at the TCU's Neeley School of Business. Because of this adaptation, the number of Neeley School students choosing to major in Business Information Systems has tripled. The course syllabus and the project booklet are available from the author for adaptation at other universities. Since the course meets basic business curriculum requirements, other schools can easily adapt it.

\section{References, additional information, and relation with Circle of Talent Development}

\section{$\underline{\text { References }}$}

Bergmann, J., \& Sams, A. (2012). How the Flipped Classroom Is Radically Transforming Learning. The Daily Riff. Available online: http:/www.thedailyriff.com/articles/how-theflipped-classroom-is-radically-transforming-learning-536.php

Buche, M. (2013). A Memory Game to Demonstrate the Power of Collaborative Efforts to Improve Team Performance. Journal of Information Systems Education, 24(3), 167- 173.

Buck Institute for Education (2018a). What is Project Based Learning? Available online: https://www.bie.org/about/what PBL

Buck Institute for Education (2018b). Why Project Based Learning? Available online: http://www.bie.org/about/why PBL

Buck Institute for Education (2018c). Resources. Available online:

http://www.bie.org/resources

Caruana, V. (2012). "Scaffolding Student Learning: Tips for Getting Started." Faculty Focus. Available online: https://www.facultyfocus.com/articles/course-design-ideas/scaffoldingstudent-learning-tips-for-getting-started/

Davidson, C. (2017). The New Education: How to Revolutionize the University to Prepare Students for a World In Flux. New York, NY: Basic Books. 
Donnelly, R. \& Fitzmaurice, M. (2005). Collaborative Project-based Learning and Problembased Learning in Higher Education: a Consideration of Tutor and Student Role in LearnerFocused Strategies. In G. O'Neill, S. Moore \& B. McMullin (Eds), Emerging Issues in the Practice of University Learning and Teaching (pp. 87-98). Dublin: AISHE/HEA.

Drake, J. (2012). A Critical Analysis of Active Learning and an Alternative Pedagogical Framework for Introductory Information Systems. Journal of Information Technology Education: Innovations in Practice (11), 39-52.

Edglossary (2015). "Scaffolding". Edglossary. Available online:

https://www.edglossary.org/scaffolding/

Educause (2012). "7 Things You Should Know About ...Flipped Classroom." Available online: https://net.educause.edu/ir/library/pdf/eli7081.pdf

Jones, B. (2015). Re-Engineering Introductory Information Systems Course for the 21st Century. Proceedings of the 2015 International Conference SIGED:IAIM. 20. Available online: https://aisel.aisnet.org/siged2015/20

Kingston, S. (2018). Project Based Learning \& Student Achievement: What Does the Research Tell Us? PBL Evidence Matters. 1(1), 1-11. Available online: http://bie.org/x9JN

Kuh, G. (2008). High -Impact Educational Practices: What They Are, Who Has Access to Them, and Why They Matter. Association of American Colleges and Universities. Available online: http://www.aacu.org/sites/default/files/files/LEAP/HIP tables.pdf

Leap Resource ToolKit (2015). Available online: http://leap.aacu.org/toolkit/high-impactpractices

Markham, T. (2012). Project Based Learning: Design and Coaching Guide. San Rafael, CA: HeartIQ Press.

Mergendoller, J., Boss, S., \& Larmer, J. (2015). Setting the Standard for Project Based Learning. Alexandria, VA: ASCD

Seeley Brown, J. (2011). A New Culture of Learning: Cultivating the Imagination for a World of Constant Change. Charleston, SC: CreateSpace Independent Publishing Platform.

Setser, B. \& Morris. H. (2015). Building a Culture of Innovation in Higher Education: Design and Practice for Leaders. Educause. Available online:

https://library.educause.edu/ /media/files/library/2015/4/ngt1502-pdf.pdf

Strobel, J., \& van Barneveld, A. (2009). When is PBL More Effective? A Meta-synthesis of Meta-analyses Comparing PBL to Conventional Classrooms. Interdisciplinary Journal of Problem-Based Learning (3)1, pp. 44-58. Available online:

http://docs.lib.purdue.edu/cgi/viewcontent.cgi?article=1046andcontext=ijPBL 
Tamim, S. \& Grant, M. (2013). Definitions and Uses: Case Study of Teachers Implementing Project-based Learning. Interdisciplinary Journal of Problem-based Learning (7)2, pp. 72-101. Available online:

http://docs.lib.purdue.edu/cgi/viewcontent.cgi?article=1323andcontext=ijPBL

\section{Relation with Circle of Talent Development}

In the introductory article of this issue of JEHC, the 'Circle of Talent Development' has been described. Based on interviews with forty honors students and literature about honors programs, it reflects relevant activities of students regarding the development of their talents in an honors program. The author of this note has been asked to score the good practice in relation to the activities in the Circle of Talent Development. The meaning of the scores is: + = somewhat important; $++=$ moderately important; +++ = very important; $-=$ not applicable or irrelevant. The scores are intended to illustrate the strengths of a good practice for the reader.

Figure 3: Circle of Talent Development in relation with the good practice 'Scaffolded, Collaborative Project-based Learning' with the teacher's scores

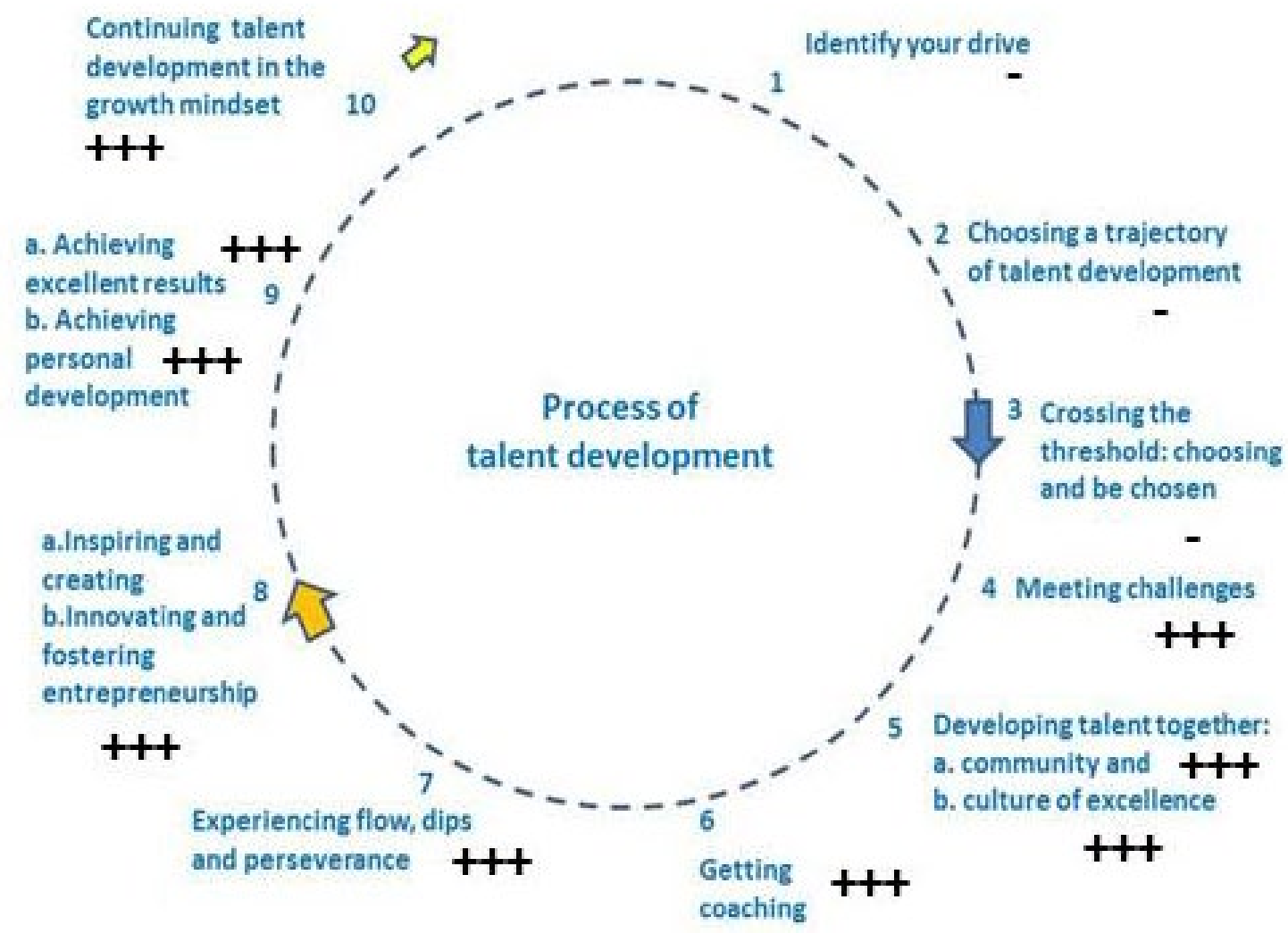

Question to the teacher: What makes this good practice attractive for other teachers? The teacher of this practice argues: 'Project-based learning incorporates the essence of honors: a real-world challenge, with bounded freedom for students to critically/creatively explore this challenge as a team, requiring reflection, which leads to deeper learning. Often, 
we use the metaphor of the Hero's Journey to capture the student journey in honors education. Similarly, in project-based learning, a team of our course "heroes" goes on a project adventure, experiences varied crises along the way, only to win a victory at the end of the course, to come home changed and transformed by the experience.' 